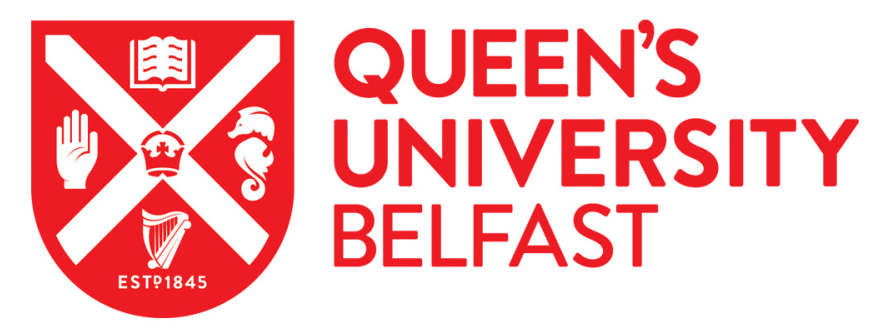

\title{
Rights based, participatory interviews with disabled children and young people: practical and methodological considerations.
}

McNeilly, P., Macdonald, G., \& Kelly, B. (2021). Rights based, participatory interviews with disabled children and young people: practical and methodological considerations. Comprehensive Child and Adolescent Nursing. https://doi.org/10.1080/24694193.2021.1874078

\section{Published in:}

Comprehensive Child and Adolescent Nursing

\section{Document Version:}

Peer reviewed version

Queen's University Belfast - Research Portal:

Link to publication record in Queen's University Belfast Research Portal

\section{Publisher rights}

Copyright 2021 Taylor \& Francis

This work is made available online in accordance with the publisher's policies. Please refer to any applicable terms of use of the publisher.

\section{General rights}

Copyright for the publications made accessible via the Queen's University Belfast Research Portal is retained by the author(s) and / or other copyright owners and it is a condition of accessing these publications that users recognise and abide by the legal requirements associated with these rights.

Take down policy

The Research Portal is Queen's institutional repository that provides access to Queen's research output. Every effort has been made to ensure that content in the Research Portal does not infringe any person's rights, or applicable UK laws. If you discover content in the Research Portal that you believe breaches copyright or violates any law, please contact openaccess@qub.ac.uk. 


\title{
Rights based, participatory interviews with disabled children and young people: practical and methodological considerations.
}

\begin{abstract}
There has been an increased emphasis on the voice of the child since the ratification of the United Nations Convention on the Rights of the Child in 1991. Since that time, health and social care researchers have increasingly involved disabled children and young people in research, rather than relying on the views of adults as proxies, for example, parents and professionals. Drawing on doctoral research and the extensive experience of the authors, the aim of this article is to critically reflect on 'what worked' along with the challenges of interviewing the children and young people who took part. Practical and methodological issues, such as the need for thorough preparation, the interview process, understanding the children and young people and managing the presence of others are discussed. Finally, recommendations are made for future researchers, including making participation fun, using a sensitive and individualised approach and conducting multiple visits. It is only by considering these factors that we can meaningfully involve disabled children and young people and facilitate their participation in research interviews. Emphasis here is on the practical issues rather than ethical issues that have been published elsewhere.
\end{abstract}

Key words: disabled, child, young person, research, involvement, interview, creative methods

\section{Introduction}

There has been an increased emphasis on the 'voice' of the child, within policy, practice and research. This has emerged as a result of guidance within the United Nations Convention on the Rights of the Child ('the Convention'), ratified in the UK in 1991. Article 12, the right of the child to express their views and have these given due weight in matters affecting them, was strengthened for disabled children and young people in the more recent Convention on the Rights of Persons with Disabilities (CRPD). According to Lansdown (2009), the aim of the CRPD is not to create new rights, but to 
ensure that existing human rights are enacted. The UK signed the Convention in 2007 (but not the optional protocol) and ratified it on $8^{\text {th }}$ June 2009. Article 7 reads as follows:

'States Parties shall ensure that children with disabilities have the right to express their views freely on all matters affecting them, their views being given due weight in accordance with their age and maturity, on an equal basis with other children, and to be provided with disability and age-appropriate assistance to realize that right.'

(Article 7, para. 3) (emphasis added)

Lundy and McEvoy (2012) point out that, while the Convention makes no reference to research, it has had a major impact on research activity concerning children. Critical discussion of a rights based approach, along with creative and participatory child oriented research methods has commanded their own place within the literature as a mechanism for helping children express their views in research (interested readers are referred to Lundy et al. 2011; Lundy and McEvoy 2012; Barker and Smith, 2012; Mand, 2012; Pimlott-Wilson, 2012; Lomax 2012; Weller, 2012; McLaughlin and ColemanFountain, 2018). However, guidance on research seeking to understand the lives of disabled children has been rather slower to develop and they are still less likely to take part in research (Tisdall, 2012; Bailey et al.2014; Ajodhia-Andrews, 2016; Jenkin et al. 2020). That is not to say that disabled children and young people should always be regarded as different or warrant 'special' consideration. Many disabled children do not experience cognitive impairment and express their views in the same ways as other children of their age (Stalker and Connors, 2003). However, it has been suggested that disabled children may be doubly (Beresford, 1997) or triply (Kelly et al. 2005) disadvantaged, with regard to expressing their views in research potentially because of the attitudes of others, the nature of their illness, impairment or their individual ways of communicating.

Drawing on doctoral research, the aim of this article is three-fold: first, to report and critically reflect on 'what worked' as regards interviewing the children and young people who took apart from the perspective of the researchers; second, to explore the challenges; and, finally, to make recommendations that may assist future researchers. 
The emphasis here is on practical and methodological issues rather than ethical issues or the findings of the research which have been previously reported (McNeilly et al.2015; 2017; 2020).

\section{Methods}

The ESRC funded study on which this paper is based aimed to explore the experiences of disabled children and young people, and their parents in decision making about health and social care. Participants included 18 disabled children and young people aged six to young adulthood from one local Health and Social Care Trust, recruited by purposeful sampling from two local advocacy groups. Participants had varying physical, cognitive, sensory and communication impairments. Five had verbal communication, ten used speech but had limited verbal expression, and three had no speech.

The study employed mixed methods based on survey methodology and interpretative phenomenology. However, the focus here will be on the interviews and participatory methods used with the children and young people (with pseudonyms used). Ethical approval was obtained from the Office for Research Ethics Committees Northern Ireland, the University and the Trust where the research was conducted. Davis (2009) and Bailey et al. (2014) highlight the importance of involving disabled children and young people in the research process. In this research, two disabled young adults from a local advocacy group acted as advisors for the study from its initial conceptualisation through to the data analysis phase. The sections that follow discuss the interview process, the use of a toolkit to assist data collection and communication, understanding the children and young people and managing the presence of others.

\section{The interview process: the preparatory phase}


Previous researchers have recommended meeting with disabled children and young people as research participants on more than one occasion (see for example, Underwood et al. 2015), and such an approach used in this study. The first visit was an introductory visit to meet the child or young person, to build rapport and find out if they were interested in taking part. This first visit also provided an opportunity to learn about the child or young person's way of communicating and to determine which data collection tools/participatory methods were most suited to and preferred by the child. Data collection (the interview) was conducted during the second visit. While this was time consuming and potentially expensive in terms of funding, it was essential in terms of reducing bias and capturing the views of children and young people in a reliable and valid way.

Because of the diversity of the children and young people, in terms of age, impairment and level of understanding, three interview schedules were prepared as recommended by previous researchers (see, for example, Kilkelly et al. 2004; Kelly, 2007). All three schedules asked the same questions in an increasingly complex format. These acted as an aide memoir, rather than a strict schedule, to preserve and foster a relaxed and natural approach to the interview. 


\section{Interview process: the data collection phase}

Children and young people had received written information and a DVD about the research in advance of the first contact, and rapport was subsequently built quickly during the first introductory meeting (see Lewis, 2001; Stalker and Connors, 2003; Kelly, 2007). A number of additional resources were used successfully to help build rapport.

Firstly, a life map or poster where children or young people were asked to identify people who were important to them. Secondly, pictures or photos of things they liked/disliked were used with or without like/dislike post boxes. A proportion of likes and dislikes pictures, symbols and photos were provided based on prior information (for example about TV programmes, cartoon characters, foods, animals) gained from parents which helped the researcher to quickly build rapport with the child.

\section{The use of the toolkit}

When conducting qualitative research, researchers have recommended offering children and young people a choice of multiple methods (see for example, Darbyshire et al. 2005; Hill, 2006; Kelly, 2007; Coyne et al. 2009;Underwood et al. 2015; Ajodhia-Andrews, 2016), and it was evident that a 'one size fits all method' would be inappropriate for this research. Jenkin et al. (2020) notes the need for a variety of methods to faciliate data collection with disabled children. In this study, an activity based-tool kit was compiled, based on previous research that sought the views of disabled children and young people (full list available from the first author) and on feedback from the two young people acting as advisors to the study. This ensured that children and young people could express their views and could be given disability and age-appropriate assistance to realise that right in keeping with Article 7 discussed earlier.

While some researchers have developed data collection tools aimed specifically at children of different age groups (for example, Coad et al. 2009), disabled children and young people may find it difficult to engage with some activities, regardless of their age, because of the nature of their impairment. Thus, in keeping with their rights, data 
collection tools in this study were selected on the basis of children and young people's preferences expressed during the first visit and, to a lesser degree, on the advice of parents or professionals who knew them well. However, it was important to enable participation in keeping with the ethos of the study. Hence children and young people selected tools they wished to use and offered help in sensitive manner if needed. Tools used, included (1) art and craft-based materials and toys (2) pictorial and verbal cues and (3) resources that helped children to indicate likes and dislikes, yes/no or to indicate agreement or disagreement. While a discussion of each is beyond the scope of this article, table 1 sets out the key advantages and limitations of the methods used. Meeting the child or young person prior to data collection and carefully considering tools that might best be suited on an individual basis was particularly useful in terms of choice of tool(s) used. Compiling the toolkit was time consuming but vital in terms of facilitating meaningful participation by those who took part. While it is noted that at times it was not possible to collect in depth data using some of these methods, they provided a vital conduit for all participants to express their views and opinions about their lives. 
While these materials provided valuable data, they also provided a mechanism to explore relevant issues further. Stalker and Connors (2003) maintain that such materials act as a distraction when children talk about their feelings, help maintain the child's interest and facilitate communication with those who use alternative means of communicating. This was evident in this study. Many children and young people clearly enjoyed the tools used and this helped engage them and maintain their interest in the topics explored:

Researcher: What did you like best of everything we've done? Did you like the boxes or the [laminated] cards or the hospital?

EOIN: I liked everything.

Researcher: You liked everything... Well do you want to do a quick drawing and I think that's us.

EOIN: Yeah!

[EOIN: 6 years old]

However, the concentration of a few children waned after a short period of time and it was important to establish if this indicated the withdrawal of consent from just one activity or participation in the research.

\section{Understanding children and young people}

Stalker and Connors (2003: 27) maintain that talking with disabled children is often no different than communicating with any other child, and the most important rule for researchers to follow is to see the child as a child first and disabled second. Nevertheless, they sometimes experienced difficulty in understanding a young person, despite having undertaken additional, advanced training in communicating with disabled children and young people (see also Crisp et al. 2002; Marchant et al. 2002; Harrison et al. 2005; Kelly, 2007). In this study, communication was optimised by using a calm, unhurried approach, and when necessary, checking back with the child or young person for clarification, to ensure accurate understanding (McNeilly, 2012). For example, a 13 year old girl with a physical impairment and very little speech indicated that she wanted to do the interview on her own. However, the researcher found it difficult to understand what she was saying and had to continually check her understanding or ask the young person to repeat her statements. As this was tiring for the 
researcher and the young person, it was necessary to check if she needed a rest or wanted to end the session:

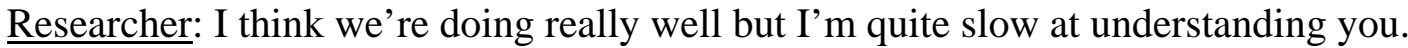
So if you're getting tired, or you want somebody in to help, will you tell me?

ORLA: [nods]

[ORLA: 13 years old]

\section{Managing the presence of others during the interviews}

The presence of parents during interviews with children has been discussed by a number of previous researchers (Macdonald and Greggans, 2008; Gardner and Randall, 2012). While parents can play an interpretive role, particularly where disabled children and young people are concerned (Turner, 2003) and they can provide much support, their presence can have unhelpful consequences. Some researchers have reported that parents of disabled children, can dominate the interview and speak for the child (Marchant et al. 1999; Lewis, 2001). When parents are present, Marchant et al. (1999) found that it was helpful to continue to engage directly with the child, to ask the child to comment on what the parent is saying, and to ask the child what they thought. In their research, Lewis (2001) and Stalker and Connors (2003) explained to parents that the researchers would like to visit children on their own and this was the strategy adopted in the present study and addressed in the parent information sheet. However, the researcher emphasised to parents that if they or their son or daughter was not happy with this arrangement then this was no problem. Most parents, children and young people had no issue with the parent not being present. All parents stayed for the first visit when their child was interviewed at home but only 6 parents stayed during data collection in the second visit because, when asked, the child or young person said they wanted their mother to be present. The child or young person's role in the research was emphasised to parents from the outset, with the result that, when they were present, the majority interpreted, prompted or encouraged their participation without speaking for them.

Siblings were sometimes present when the researcher arrived at the house and this could be challenging and required sensitive handling. Lewis (2001) noted that, in her research, siblings needed to be distracted and provided with their own activities before she could conduct the 
session with the research participant. In this study, a younger sibling who, on arrival for the first visit, was watching her sister making a picture from the stairway, was later invited to join in and draw a picture as well and both were given a sticky badge when the researcher was leaving. On another occasion, with the agreement of the child, a 12 year old sibling played an important interpretive role.

\section{Discussion}

The aim of this article was three-fold: to report and critically reflect on 'what worked' as regards interviewing the children and young people who took apart in this research, to explore the challenges, and to make recommendations that may assist future researchers. As stated earlier, disabled children and young people have the right to express their views freely on all matters affecting them on an equal basis with other children, and should be provided with disability- and age-appropriate assistance to realize that right. In this article we have discussed 'what worked' in addition to the challenges encountered in the planning and conduct of doctoral research, and what other researchers have found to be both helpful and challenging (Lewis, 2001; Stalker and Connors, 2003; Kilkelly et al. 2004; Harrison et al. 2005; Rabiee et al. 2005; Kelly, 2007). Lundy and McAvoy (2012) point out that a rights based approach needs to be adopted during the planning stage of research, in order to ensure that its conduct is rights based. As such, in this study, input from two disabled young adults was particularly beneficial around the use of participatory and creative methods of data collection that facilitated the wide participation of children and young people. Based on the authors' experiences and the content presented earlier in this article, recommendations for future researchers planning to interview disabled children and young people have been set out (see Box 1).

Moving forward, Lundy et al. (2011) discuss the need to involve young children as coresearchers whilst recognising that there are limits to what they might want to do. Similarly, more emphasis is needed on building capacity in disabled children and young people to enable them to take on the role of peer researchers as experts in their own lives (Kelly et al. 2017). Jenkin et al. (2020) have produced a set of principles for researching with disabled 
children. Additionally inter-professional guidelines (addressing specific practical and ethical issues) for researching with disabled children and young people should be developed in partnership with them and other key stakeholders.

\section{Strengths and limitations of the research}

Like all research, this study has strengths and limitations. Guidance from both reference groups was vital in this study as discussed earlier. A further strength was the experience of the projects' supervisors both as social workers and as researchers in designing the study and guiding the research process. My own experience of working with children, young people and families as a children's nurse both in the hospital and community setting for many years was also a strength. Researching with disabled children and young people, in particular, presents many challenges to the novice researcher. A further strength of this study was the effort put into designing a variety of data collection tools and mechanisms to engage children and young people in the process of informed consent in a meaningful way. The first author's previous work on researching with disabled children and young people, a dissertation for a MRes (Masters in social research methods), was invaluable when meeting and collecting data with children and young people.

Nevertheless, this study also had limitations. While it is acknowledged that the number of children and young people in this study was relatively small, generalisability to the population as a whole was not the aim of this study. The co-morbidity of children and young people's impairments did not allow for in depth analysis of specific issues for those with physical, cognitive, sensory or communication impairments. Researching with disabled children and young people has additional challenges but this should not preclude their participation in research.

\section{Conclusion}

Disabled children and young people have a wealth of knowledge and experience that can help shape the health and social care services that they use. In order to elicit their views, researchers need to develop a range of skills and methods and be both proactive and responsive when conducting research. While there is an emerging literature relating to researching with disabled children (Mitchell et al. 2009; Stalker and Connors; Stalker, 2012; 
Bailey et al. 2014), more critical and open discussion is needed about the inherent challenges that can arise, how these may be surmounted and essentially what works within this field of research. In so doing we can ensure that disabled children and young people participate in research on an equal basis with other children. 


\section{Declaration of interest statements}

No conflict of interest

\section{References}

Ajodhia-Andrews, A (2016) Reflexively conducting research with ethnically diverse children with disabilities. The Qualitative Report, 21(2), 252-287.

Bailey, S, Boddy, S, Briscoe, S, Morris, C (2014) Involving disabled children and young people as partners in research: a systematic review. Child: Care, Health and Development, 41(4), 505-514.

Barker, J and Smith, F (2012) What's in focus? A critical discussion of photography, children and young people. International Journal of Social Research Methodology, 15(2), 91-103.

Beresford, B. (1997) Personal Accounts: Involving disabled children in research.London: The Stationary Office.

Coad, J., Plumridge, G. and Metcalfe, A. (2009) Involving children and young people in the development of art-based research tools.NurseResearcher, 16(4), 56-64.

Coyne, I., Hayes, E. and Gallagher, P. (2009) Research with hospitalised children.Ethical, methodological and organisational challenges.Childhood, 16(3), 413-429.

Crisp, A., Marchant, R. and Simon, J. (2002) 'I've been there'. What you told us about the services you use.The views of children and young people in Westminster.Brighton: Triangle.

Darbyshire, P., Macdougall, C. and Schiller, W. (2005) Multiple methods in qualitative research with children: more insight or just more?Qualitative Research, 5(4), 417-436.

Davis, J. (2009) Involving children.InTisdall, E. Kay M., Davis, J. M. and Gallagher, M. (Eds) Researching with children and young people. Research, design, methods and analysis.London: Sage.

Gardner, H. and Randall, D. (2012) The effects of the presence or absence of parents on interviews with children.NurseResearcher, 19(2), 6-10.

Harrison, G., Tuckett, P. and Marchant, R. (2005) 'Shape it up a bit'.Consultation with disabled children and young people in Tower Hamlets. East Sussex: Triangle.

Hill, M. (2006) Children's voices on ways of having a voice: Children's and young people's perspectives on methods used in research and consultation.Childhood, 13, 69-89.

Jenkin, E, Wilson, E, Campain, R and Clarke, M (2020) The principles and ethics of including children with disability in research. Children and Society, 34, 1-16. 
Kelly, B. (2005) ‘Chocolate...makes you autism': impairment, disability and childhood identities.Disability and Society, 20(3), 261-275.

Kelly, B. (2007) Methodological issues for qualitative research with learning disabled children. International Journal of Social Research Methodology, 10 (1), 21-35.

Kelly, B., Gilligan, E., Friel, S., Smith, D., Pinkerton, J. \& McShane, T. (2017) More than we expected! A guide to peer research with young people. Belfast: QUB \& VOYPIC.

Kilkelly, U., Kilpatrick, R., Lundy, L., Moore, L., Scraton, P., Davey, C., Dwyer, C., McAlister, S. (2004) Children's Rights in Northern Ireland. Research commissioned by the NI commissioner for children and young people. Available at:

http://dera.ioe.ac.uk/9165/1/22323\%20Final.pdf Accessed 23/4/17.

Lansdown, G.(2009) See me, hear, me A guide to using the UN Convention on the Rights of Persons with Disabilities to promote the rights of children.London: Save the Children.

Lewis, M. (2001) Learning to listen. Consulting children and young people with disabilities.UK: Save the Children. Available at http://www.savethechildren.org.uk/sites/default/files/docs/Learning_to_listen_1.pdf Accessed 23/4/17.

Lomax, H. (2012) Contested voices? Methodological tensions in creative visual research with children.International Journal of Social Research Methodology, 15(2), 105-117.

Lundy, L, McEvoy, L and Byrne, B (2011) Working with young children as co-Researchers. Early Education and Development, 22(5), 714-736.

Lundy, L and McEvoy, L (2012) Childhood, the United Nations Convention on the rights of the child and research: What constitutes a rights-based approach? In Freeman, M (Ed) Law and Childhood Studies: Current Legal Issues Vol 14. UK: Open University Press.

Macdonald, K. and Greggans, A. (2008) Dealing with chaos and complexity: the reality of interviewing children and families in their own homes. Journal of Clinical Nursing, 17, 31233130 .

Mand, K (2012) Giving children a 'voice': arts-based participatory research activities and representation. International Journal of Social Research Methodology, 15(2), 149-160.

Marchant, R., Jones, M., Julyan, A. and Giles, A. (1999) "Listening on all channels" Consulting with disabled children and young people. East Sussex: Triangle.

Marchant, R., Tuckett, P. and Kirby, P. (2002) The best thing... What you told us about the services you use. The views of children and young people in Greenwich. East Sussex: Triangle.

Mitchell, W, Franklin, A, Greco, V and Bell, M (2009) Working with children with learning disabilities and /or who communicate non-verbally: Research experiences and their implications for social work education, increased participation and social inclusion. Social Work Education, 28(3), 309-324. 
McLaughlin, J and Coleman-Fountain, E (2018) Visual methods and voice in disabled childhoods research: troubling narrative authenticity. Qualitative research, 19(4), 363-381

McNeilly, P. (2012) Communicating with the child or young person with special needs. In Dawson, P, Cook, L, Holliday, L J , Reddy, H (Eds) Oxford handbook of children and young people's nursing. UK: OUP

McNeilly, P, Macdonald, G and Kelly, B (2015) The participation of disabled children and young people: a social justice perspective. Childcare in Practice, 21(3), 266-286.

McNeilly, P, Macdonald, G and Kelly, B (2017) The participation of parents of disabled children and young people in health and social care decisions. Child: Care, Health and Development, 43, Issue 6839-846

McNeilly, P, Macdonald, G and Kelly, B (2020) Ethical considerations when conducting research with children and young people with disabilities in health and social care. Nurse Researcher. DOI: 10.7748/nr.2020.e1645.

Pimlott-Wilson, H (2012) Visualising children's participation in research: Lego, duplo, rainbows and cloud and moodboards. International Journal of Social Research Methodology, 15(2),135-148.

Rabiee, P., Sloper, P. and Beresford, B. (2005) Doing research with children and young people do not use speech for communication. Children and Society, 19, 385-396.

Sloper, P., Beresford, B. and Rabiee, P. (2009) Every child matters outcomes: What do they mean for disabled children and young people? Children and Society, 23(4), 265-278.

Stalker, K. and Connors, C. (2003) Communication with disabled children.Adoption and Fostering, 27 (1), 26-35.

Stalker, K (2012) Researching the lives of disabled children and young people (Editorial).

Underwood, K, Chan, C, Koller, D and Valeo, A (2015) Understanding young children's capabilities: approaches to interviews with young children experiencing disability. Child Care in Practice, 21(3),220-237.

Weller, S (2012) Evolving creativity in qualitative longitudinal research with children and teennagers. International Journal of Social Research Methodology, 15(2), 119-13 